\title{
ALTERAÇÕES PÓS-COLHEITA DA “FRUTA-DE-LOBO” (Solanum lycocarpum St. Hil.) DURANTE O AMADURECIMENTO: Análises físico-químicas, químicas e enzimáticas ${ }^{1}$
}

\author{
ENIO NAZARÉ DE OLIVEIRA JUNIOR², CUSTÓDIO DONIZETE DOS SANTOS ${ }^{3}$, CELESTE MARIA PATTO DE \\ ABREU $^{4}$, ANGELITA DUARTE CORRÊA ${ }^{4}$, JOSÉ ZILTON LOPEZ SANTOS
}

\begin{abstract}
RESUMO - Estudaram-se, neste trabalho, algumas modificações físico-químicas, químicas e enzimáticas, em pós-colheita, durante o amadurecimento da fruta-de-lobo, comparando-as com as de outros frutos. Os frutos colhidos de plantas nativas no início do estádio de amadurecimento foram selecionados e armazenados durante 18 dias à temperatura ambiente $\left(17,1\right.$ a $\left.26,9^{\circ} \mathrm{C}\right)$. Os frutos foram lavados com água destilada, descascados, picados, congelados em nitrogênio líquido e liofilizados até massa constante. O delineamento experimental utilizado foi o inteiramente casualizado, com quatro repetições de 3 frutos. Os valores de $\mathrm{pH}$ e acidez titulável não variaram estatisticamente durante o amadurecimento. A atividade de amilase e os teores de amido diminuíram gradativamente com o aumento dos açúcares solúveis totais e não redutores, enquanto os teores dos redutores se mantiveram constantes. Os teores de pectinas totais e solúveis diminuíram, enquanto a atividade de pectinametilesterase manteve-se constante. As atividades das enzimas poligalacturonase e polimetilgalacturonase não foram detectadas no fruto. Observou-se diminuição dos teores de polifenóis e das atividades das enzimas peroxidase e polifenoloxidase e conseqüente diminuição do escurecimento da polpa do fruto.
\end{abstract}

Termos de indexação: polifenóis, peroxidase, polifenoloxidase, poligalacturonase, polimetilgalacturonase, pectinametilesterase

\section{POSTHARVEST CHANGES OF “FRUTA-DE-LOBO” (Solanum lycocarpum St. Hil.) DURING THE RIPENING} PROCESS: physical-chemical, chemical and enzymatic analysis

\begin{abstract}
Physical-chemical, chemical and enzymatic modifications were studied during the ripening of "fruta-de-lobo" compared with those in other fruits. The fruits were harvested from native plants in the ripening initial stage and they were selected and stored during 18 days at room temperature $\left(17.1\right.$ to $\left.26.9^{\circ} \mathrm{C}\right)$. The fruits were washed with distilled water and peeled. Their pulps were chopped up, frozen in liquid nitrogen and lyophilized until they get a constant mass. The $\mathrm{pH}$ and tritable acidity did not show statistical variation during the ripening process. The amylase activity and the starch contents decreased gradually and the soluble total sugar and nonreducing sugar increased while the reducing sugar contents maintained constant. The polygalacturonase and polymetilgalacturonase activities were not detected in the fruit. It was observed that the browning of fruit pulp decreased due to the decreasing of polyphenol contents and the peroxidase and polyphenoloxidase activities.
\end{abstract}

Index terms: polyphenols, peroxidase, polyphenoloxidase, polygalacturonase, polymetilgalacturonase, pectinmethylesterase.

\section{INTRODUÇÃO}

A procura por novos alimentos, alternativos e seguros, motivou um estudo sobre algumas modificações pós-colheita que ocorrem durante o amadurecimento da fruta-de-lobo ou fruto da lobeira (Solanum lycocarpum St. Hil.). A espécie vegetal Solanum lycocarpum St. Hil. atinge até $4 \mathrm{~m}$ de altura, sendo muito ramosa e revestida de densos pêlos estrelados, ramos cilíndricos, lenhosos, fistulosos, um pouco tortuosos e folhas pecioladas (Corrêa, 1984). As plantas podem apresentar de 40 a 100 frutos, cuja massa por fruto pode variar de 400 a $900 \mathrm{~g}$, com época de colheita de julho a janeiro (Silva et al., 1994). Acredita-se que seu nome vulgar se deve ao fato de se constituir um alimento preferido do lobo-guará. A fruta-de-lobo, quando verde, é constituída de polpa bastante firme de coloração branca, mas quando o fruto se torna totalmente maduro, a polpa passa a apresentar uma coloração amarelada, macia, adocicada e extremamente aromática, o que levou os sertanejos a se interessarem pelo fruto (Oliveira Junior, 2002).

Oliveira Junior et al. (2003) analisaram alguns nutrientes da fruta-de-lobo durante o amadurecimento e encontraram vitamina $\mathrm{C}$ $(85 \mathrm{mg})$, açúcares solúveis totais $(11 \mathrm{~g})$, sacarose $(8,6 \mathrm{~g})$, fósforo $(35,5 \mathrm{mg})$ e ferro $(1,2 \mathrm{mg})$ em $100 \mathrm{~g}$ de polpa fresca. Os autores observaram que os teores encontrados na fruta-de-lobo, comparados aos de outros frutos, como abacaxi, banana, laranja, manga, entre outros, são equivalentes ou superiores aos dos frutos em questão, concluindo-se que o fruto da lobeira representa mais uma alternativa como fonte desses nutrientes.

Neste trabalho, estudaram-se algumas modificações físicoquímicas, químicas e enzimáticas, em pós-colheita, durante o amadurecimento da fruta-de-lobo.

\section{MATERIAISEMÉTODOS}

Os frutos foram colhidos, após as 16 horas, levando-se em conta os seguintes critérios de seleção: estádio de amadurecimento, tamanho, cor da casca (verde intenso), pedúnculo totalmente preso e ausência de injúrias provocadas por insetos ou por choques mecânicos. Foram selecionados 120 frutos armazenados durante 18 dias. As temperaturas mínima e máxima observadas durante o período de amadurecimento foram, em média, 17,1 e $26,9^{\circ} \mathrm{C}$ respectivamente. A cada 2 dias, 12 frutos foram selecionados, lavados com água destilada, descascados, tendo suas polpas picadas, congeladas em nitrogênio líquido e liofilizadas em Liofilizador Labconco Freeze Dry System/ Freezone 4,5, durante 3 dias. Em seguida, as amostras foram moídas em moinho refrigerado por 3 períodos de 3 segundos, sob rotação de 22.500 rpm e temperatura de $4^{\circ} \mathrm{C}$. As amostras foram armazenadas em recipiente de vidro hermeticamente fechado e protegido da luz à temperatura ambiente e submetidas às análises. Sólidos Solúveis (SS), Acidez Titulável (AT) e pH: determinou-se o teor de sólidos solúveis por leitura em refratômetro digital, modelo Pr-100, Palette (Atago Co., LTD., Japão). O pH e a acidez titulável foram determinados segundo AOAC (1990). Extração e Análise de Açúcares Solúveis Totais (AST), Açúcares Não Redutores (ANR) e Açúcares Redutores (AR): extração pelo método de Lane-Enyon (AOAC, 1990) e quantificação (Noelting e Bernfeld, 1948). Extração e Análise de Amido: extração e hidrólise de amido segundo técnica citada por Arêas e Lajolo (1980), e a quantificação de amido hidrolisado a glicose foi feita segundo a técnica descrita por Dahlqvist (1968). Extração e Atividade de Amilase: amilase (EC 3.4.1.161) extração (Karder, 1992) com modificações (Oliveira Junior, 2002). Quantificação dos açúcares redutores formados (Noelting \& Bernfeld, 1948). Extração

\footnotetext{
(Trabalho 006/2004). Recebido: 02/01/2004. Aceito para publicação: 19/11/2004.

${ }^{2}$ Engenheiro Químico, Mestre em Agronomia, concentração Agroquímica e Agrobioquímica, UNIVERSIDADE FEDERAL DE LAVRAS (UFLA), caixa postal 37, 37200-000 Lavras-MG.enionazare@yahoo.com.br

${ }^{3}$ Engenheiro Agrônomo, D.S. Ciências, Professor Titular do Departamento de Química/UFLA.

${ }^{4}$ Engenheiro Agrônomo, D.S. Ciências dos Alimentos, Professora Adjunta do Departamento de Química/UFLA.

${ }^{5}$ Engenheiro Agrônomo/UFLA.
} 
e Análise de Polifenóis: extraídos segundo Goldstein \& Swain (1963) com modificações (Oliveira Junior, 2002) e quantificados pelo método de Folin-Denis (AOAC, 1990). Extração e Atividade de Peroxidase (PER) e Polifenoloxidase (PFO): segundo técnica descrita por Maarten et al. (1997) com modificações (Oliveira Junior, 2002). Extração e Análise de Pectina Total (PT) e Pectina Solúvel (PS): extração (McCready \& McComb, 1952) e quantificação (Bitter \& Muir, 1962). Extração eAtividade de Poligalacturonase (PG), Polimetilgalacturonase (PMG) e Pectinametilesterase (PME): extração segundo Alonso et al. (1995) com modificações (Oliveira Junior, 2002). Quantificação dos grupos redutores (Nelson, 1944). Análise Estatística: delineamento experimental inteiramente casualizado, 10 tempos de armazenamento, 4 repetições e 3 frutos por repetição. Os resultados foram analisados por meio de análise de variância e de regressão, a 5\% de probabilidade, sendo os modelos selecionados mediante o coeficiente de determinação, e da significância dos coeficientes de regressão, testados pelo teste t de Student.

\section{RESULTADOS E DISCUSSÕES}

A desidratação das amostras ocorreu após 3 dias de liofilização, tempo suficiente para que a massa da amostra permanecesse constante, retirando das amostras, em média, 71,4\% de umidade.

Os teores dos SS aumentaram com o amadurecimento da frutade-lobo (Figura 1), assim como se observa durante o amadurecimento da maioria dos frutos. O aumento observado nos teores de SS pode ser explicado pela diminuição dos teores de amido e, conseqüentemente, aumento dos teores de açúcares solúveis totais (Oliveira Junior et al., 2003). Os teores médios de SS encontrados para o fruto verde (dia 0) e maduro (dia 18) foram, respectivamente, $1,57 \%$ e 3,70\% (Figura 1).

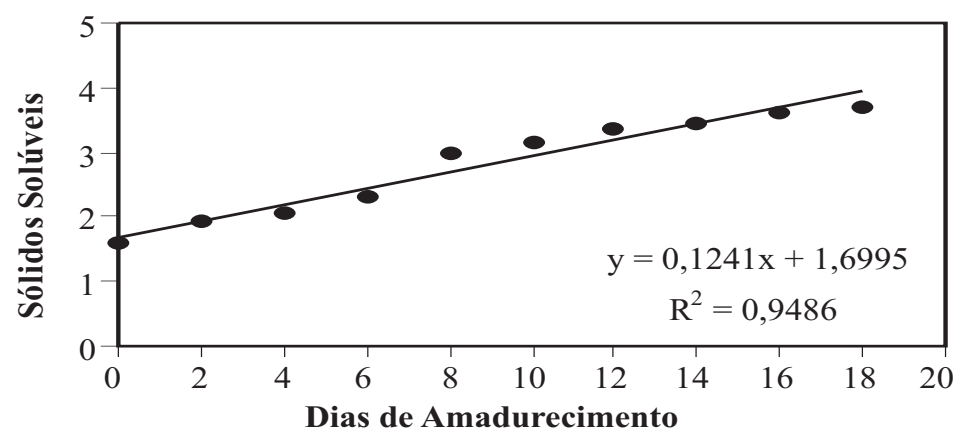

FIGURA 1 - Teores médios de sólidos solúveis (\%) durante o amadurecimento da fruta-de-lobo $(\mathrm{p}=0,05)$

Os valores médios de pH e da AT (equivalentes de ácido cítrico/ $100 \mathrm{~g}$ de polpa fresca) não variaram significativamente $(\mathrm{p}=0,05)$ durante o amadurecimento (Tabela 1). Corrêa et al. (2000), estudando fruta-delobo, e Filgueiras (1996), estudando tomate, encontraram diferença significativa no valor de $\mathrm{pH}$, porém não encontraram variação significativa no teor de AT. Os valores médios de $\mathrm{pH}$ e AT neste trabalho foram, respectivamente, 4,42 e 0,78 (equivalentes de ácido cítrico/ $100 \mathrm{~g}$ de polpa fresca). Segundo Chitarra \& Chitarra (1990), frutos com o amadurecimento perdem rapidamente a acidez; mas, em alguns casos, há um pequeno aumento nos teores com o avanço do amadurecimento.

Simultaneamente à diminuição da atividade da enzima amilase durante o amadurecimento do fruto (Figura 4), observou-se diminuição dos teores de amido e conseqüente aumento dos teores de açúcares solúveis totais e não redutores (Figuras 2 e 3), verificando-se que a enzima é uma das principais responsáveis pela hidrólise do amido do fruto em oligossacarídeos.

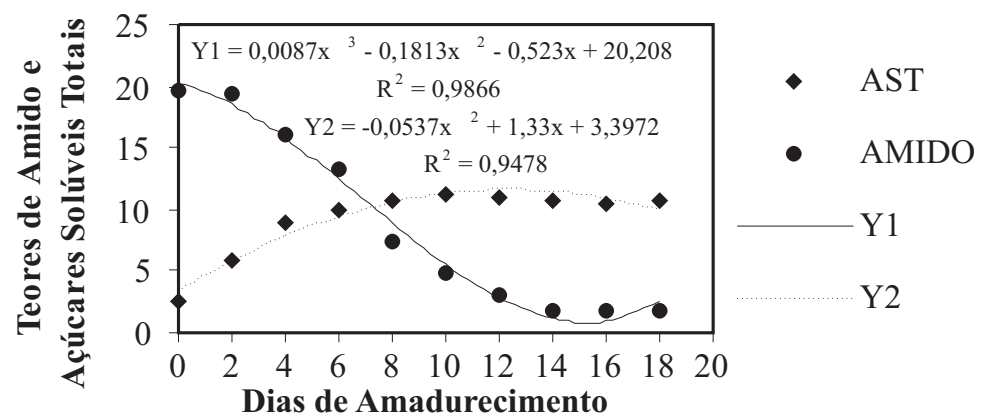

FIGURA 2 - Teores médios de amido e açúcares solúveis totais (AST), (g de glicose $/ 100 \mathrm{~g}$ de polpa fresca) durante o amadurecimento da fruta-de-lobo $(\mathrm{p}=0,05)$.

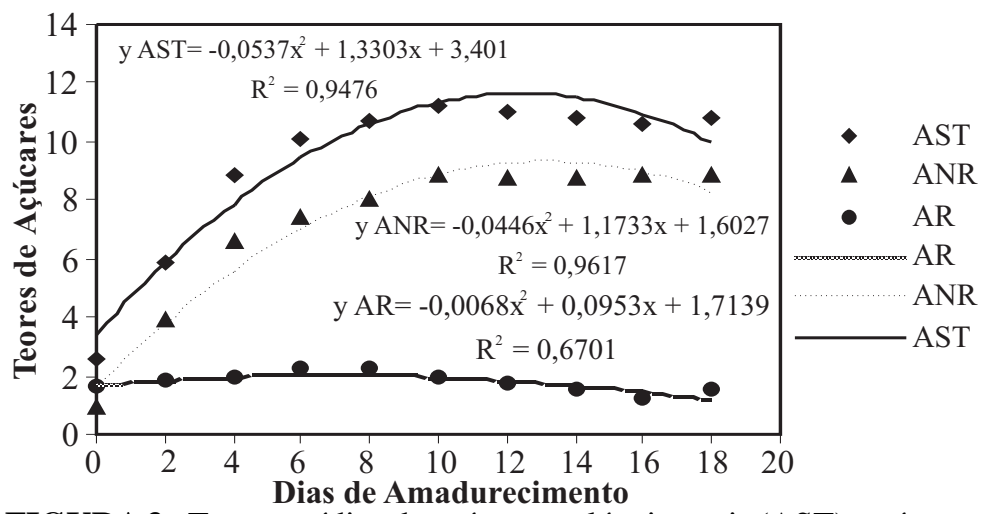

FIGURA 3 - Teores médios de açúcares solúveis totais (AST), açúcares não-redutores (ANR) e açúcares redutores (AR) em g de glicose $/ 100 \mathrm{~g}$ de polpa fresca durante o amadurecimento da fruta-de-lobo $(\mathrm{p}=0,05)$.

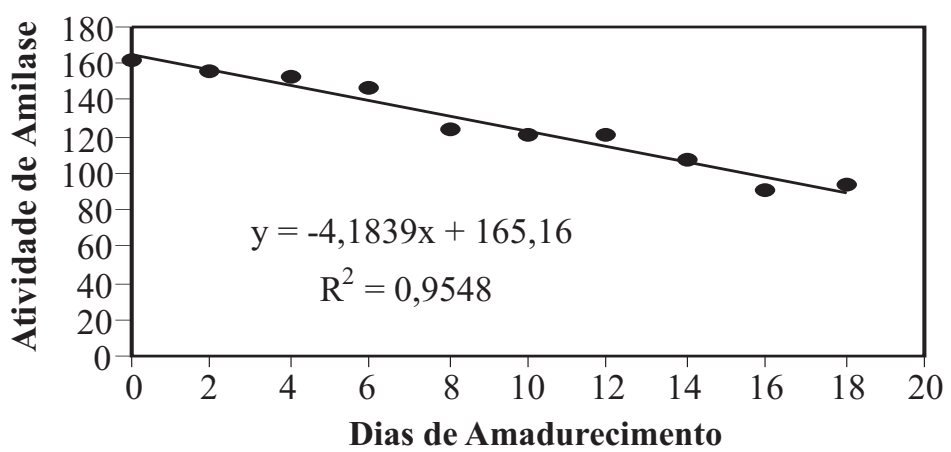

FIGURA 4 - Atividade de amilase (U/100 g de polpa liofilizada) durante o amadurecimento da fruta-de-lobo $(\mathrm{p}=0,05)$.

Com o decorrer do amadurecimento, observou-se decréscimo acentuado dos teores de polifenóis até o $14^{\circ}$ dia de amadurecimento (44,21 mg de ácido tânico/100 g de polpa fresca), ocorrendo um pequeno aumento a partir desse estádio (Figura 5). Um dos fatores que explica a diminuição dos teores dos polifenóis é que, durante a maturação dos frutos, há um aumento gradual na condensação dos fenólicos solúveis, tornando-os insolúveis por se ligarem fortememente a outros componentes celulares, não sendo, portanto, detectados (Chitarra \& Chitarra, 1990).

Observou-se que os valores da atividade de PER diminuíram gradativamente durante o amadurecimento da fruta-de-lobo (Figura 6), assim como foi observada diminuição nos teores de polifenóis (Figura 5). A diminuição da atividade da enzima PER pode estar relacionada à diminuição dos teores de polifenóis durante o amadurecimento da fruta-

TABELA 1 - Acidez titulável (AT) em equivalentes de ácido cítrico/ $100 \mathrm{~g}$ de polpa fresca e pH durante o amadurecimento da fruta-de-lobo.

\begin{tabular}{ccccccccccccc}
\hline Dias & 0 & 2 & 4 & 6 & 8 & 10 & 12 & 14 & 16 & 18 & $\mathbf{C V}^{*}$ \\
\hline $\mathbf{p H}$ & 4,50 & 4,45 & 4,46 & 4,42 & 4,36 & 4,47 & 4,46 & 4,48 & 4,31 & 4,30 & 1,91 \\
AT & 0,75 & 0,77 & 0,76 & 0,83 & 0,78 & 0,80 & 0,73 & 0,78 & 0,78 & 0,84 & 8,91 \\
\hline
\end{tabular}


de-lobo, em virtude do aumento gradual na condensação dos fenólicos solúveis, tornando-os insolúveis por esses se ligarem fortemente a outros componentes celulares e, conseqüentemente, tornarem-se indisponíveis à ação da enzima PER. No dia da colheita do fruto, foi encontrada a maior atividade de PER, ou seja, 281,92; ao passo que, no estádio final de amadurecimento, a atividade foi de $24,00 \mathrm{mU} / \mathrm{g}$ de polpa liofilizada.

Durante todos os estádios de amadurecimento da fruta-de-lobo, observou-se atividade da enzima PFO. As atividades dessa enzima no fruto verde (dia 0) e fruto maduro (dia 18) foram, respectivamente, $3,69 \mathrm{e}$ $1,06 \mathrm{U} / \mathrm{g}$ de polpa liofilizada. Do estádio inicial (dia 0) até o $12^{\circ}$ dia de amadurecimento, houve aumento da atividade de PFO de 3,69 para 5,79 U/g de polpa liofilizada, que declinou após esse estádio até o final do amadurecimento (Figura 7).

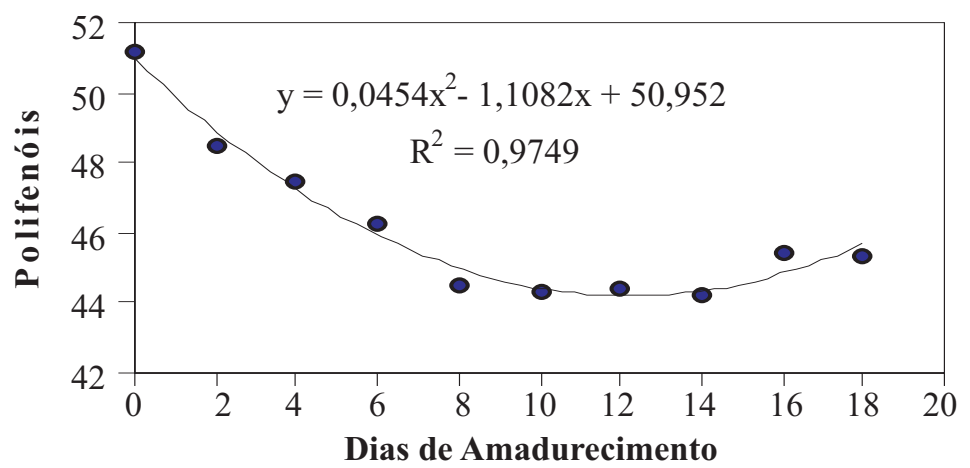

FIGURA 5 - Teores médios de polifenóis (mg de ácido tânico/100 g de polpa fresca) durante o amadurecimento da fruta-de-lobo $(\mathrm{p}=0,05)$.

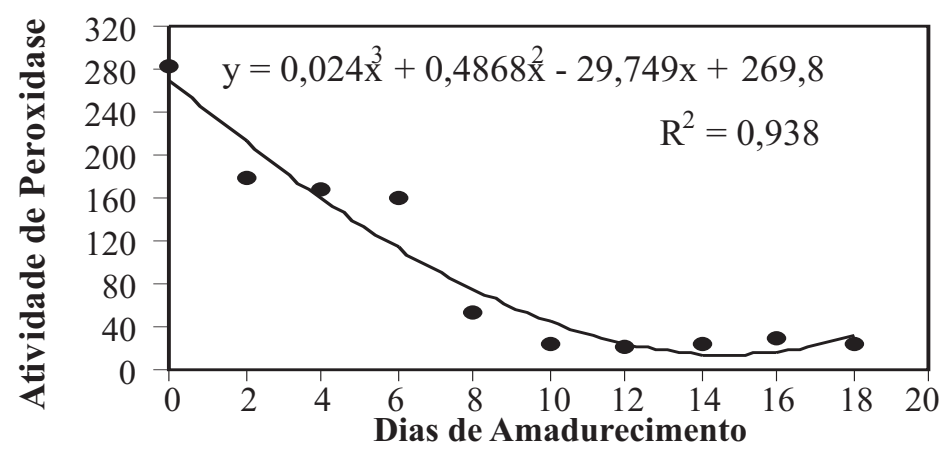

FIGURA 6 - Atividade de peroxidase (mU/g de polpa liofilizada) durante o amadurecimento da fruta-de-lobo $(\mathrm{p}=0,05)$.

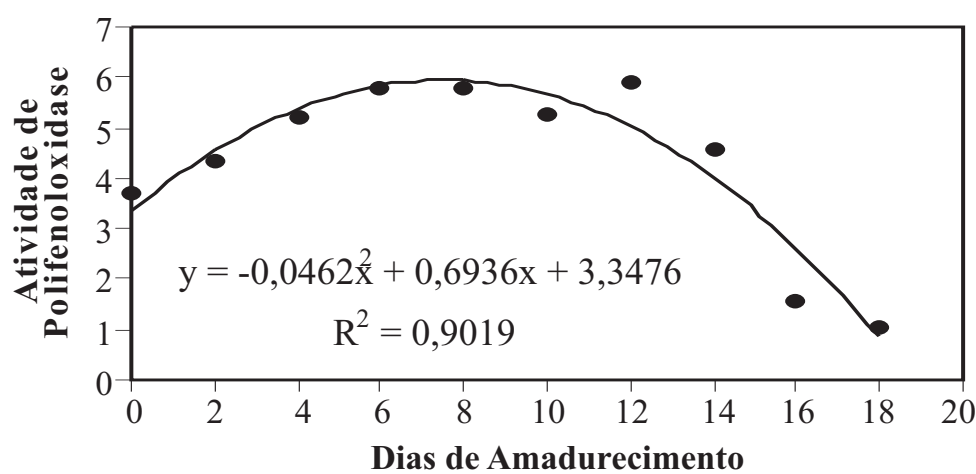

FIGURA 7 - Atividade de polifenoloxidase (U/g de polpa liofilizada) durante $\mathrm{o}$ amadurecimento da fruta-de-lobo $(\mathrm{p}=0,05)$.

O escurecimento na polpa de muitos frutos tem sido atribuído à atividade de PER e PFO em abacaxi (Abreu, 1991), à atividade de PFO em abacate (Seymour et al., 1993), e em maçã (Nicolas et al., 1994).
A diminuição nos teores de polifenóis, juntamente com as diminuições também observadas nas atividades das enzimas PER e PFO são alguns dos fatores que podem estar envolvidos na diminuição do escurecimento da polpa da fruta-de-lobo durante o seu amadurecimento.

Os teores médios (mg de ácido galacturônico/100 g de polpa fresca) de PT encontrados na polpa da fruta-de-lobo aumentaram durante o amadurecimento, de 852,92 (dia 0) até 2.702,15 (dia 14), diminuindo para $1.928,76$ no $18^{\circ}$ dia de amadurecimento (Figura 8). Resultado similar foi observado nos teores de PS, que aumentaram gradativamente durante o amadurecimento de 417,78 a 1.388,28, respectivamente, no (dia 0 ) fruto verde e no (dia 18) fruto maduro (Figura 8 ).

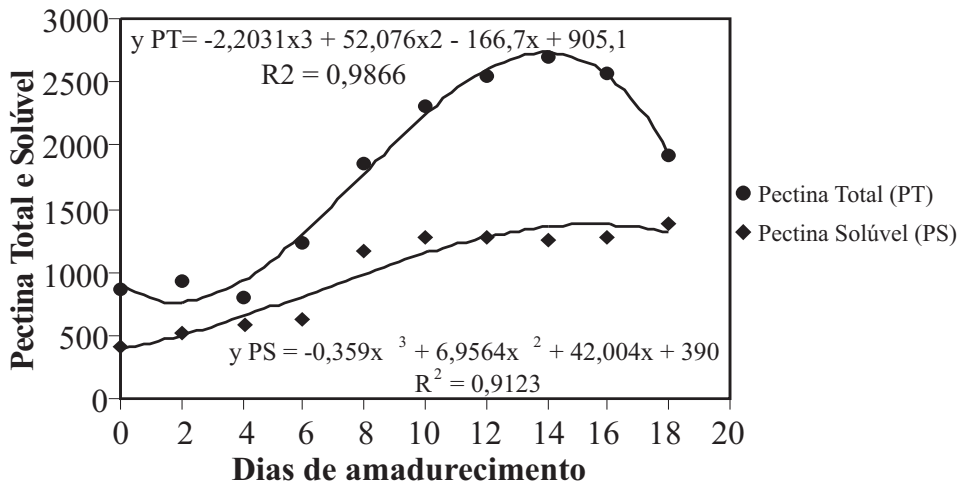

FIGURA 8 - Teores médios de pectinas total e solúvel (mg de ácido galacturônico /100 g de polpa fresca) durante o amadurecimento da fruta-de-lobo $(\mathrm{p}=0,05)$.

Tais resultados estão de acordo com os encontrados durante o amadurecimento de banana (Vilas Boas, 1995), de abacaxi (Abreu, 1995) e fruta-de-lobo (Corrêa et al., 2000), que observaram aumento nos teores de PT e de PS. O aumento de PT observado no presente estudo pode estar relacionado à eficiência da metodologia de extração da PT quando o fruto está verde, o que sugere que a pectina dentro da parede está em uma forma não acessível pela pectinase EC 3.2.1.15, e a eficiência de extração talvez possa aumentar com o amadurecimento, já que a maioria dos polissacarídeos sofre hidrólise com o avanço do amadurecimento.

As atividades das enzimas PG (EC 3.2.1.15) e PMG (EC 3.2.1.15) não foram detectadas no presente estudo, durante o amadurecimento da fruta-de-lobo. A essas pectinases são atribuídas a despolimerização de pectinas desestereficadas e altamente esterificadas, respectivamente.

A atividade de PME foi detectada em todos os estádios de amadurecimento do fruto (Tabela 2), e a atividade média foi de 17,10 U.

No presente estudo, dentre as enzimas citadas, não existem evidências que relacionem o processo de amaciamento do mesocarpo da fruta-de-lobo, ou seja, aumento nos teores de PS com as enzimas PG e PMG. Apesar de se ter detectado atividade da enzima PME, uma das pectinases envolvidas no processo de amaciamento, com conseqüente aumento nos teores de PS, não se pode inferir que somente essa enzima esteja envolvida no processo de degradação, mas pode estar envolvida no processo de solubilização das pectinas, já que as pectinas com alto grau de esterificação são pouco solúveis em água, e as desesterificadas (ácidos poligalacturônicos) são altamente solúveis em água. Segundo Cutillas-Iturralde et al. (1993), o mesmo resultado foi encontrado durante amadurecimento de caquis (Dyospyros kaki L.), observando-se mudanças na textura da parede, acompanhadas de extremo amaciamento da polpa, sem atividade de endo e exo-PG, concluindo-se que essa enzima não seria responsável pelo metabolismo de pectinas neste fruto.

Estudando a qualidade pós-colheita de melão tipo 'Galia'

TABELA 2 - Atividade de pectinametilesterase (U) em função do amadurecimento da fruta-de-lobo.

\begin{tabular}{cccccccccccc}
\hline Dias & 0 & 2 & 4 & 6 & 8 & 10 & 12 & 14 & 16 & 18 & CV $^{*}$ \\
\hline PME & 16,27 & 16,70 & 17,25 & 18,15 & 19,10 & 19,20 & 17,20 & 16,90 & 14,85 & 15,05 & 18,40 \\
\hline \multicolumn{10}{c}{ *Coeficiente de variação } & &
\end{tabular}


durante a maturação e o armazenamento, Menezes (1996) observou que as atividades das enzimas PG e PME permaneceram constantes ou declinaram. Durante o amadurecimento de banana (Vilas Boas, 1995) e de tomate (Filgueiras,1996), os autores citados observaram que as atividade das enzimas PG e PME apresentaram oscilações durante o amadurecimento dos frutos. Já, Abreu (1995) observou que, durante o amadurecimento de abacaxi, as atividades das enzimas PG e PME, assim como a solubilização de pectinas aumentaram gradativamente.

Comparando-se os resultados encontrados nos frutos estudados, observa-se que, dependendo do tipo de fruto, a atividade da enzima PG pode aumentar, diminuir, permanecer constante ou simplesmente não apresentar atividade, ao passo que a enzima PME pode aumentar, diminuir ou permanecer constante durante o amadurecimento. Assim, são necessários mais estudos para se tentar elucidar o processo de amaciamento da polpa da fruta-de-lobo durante o seu amadurecimento, já que a parede celular é uma estrutura extremamente complexa, e, dessa maneira, várias enzimas podem estar envolvidas no processo de sua degradação.

\section{CONCLUSÕES}

Pelos resultados, nas condições em que o experimento foi realizado, pode-se concluir que as alterações pós-colheita avaliadas durante o amadurecimento da fruta-de-lobo apresentaram comportamento semelhante ao de outros frutos em relação à atividade de amilase, teores de amido, sólidos solúveis, açúcares solúveis totais, $\mathrm{pH}$, acidez titulável, polifenóis e às atividades das enzimas peroxidase e polifenoloxidase. Dentre as enzimas associadas ao amaciamento da polpa do fruto, detectou-se atividade apenas de pectinametilesterase, enquanto as enzimas poligalacturonase e polimetilgalacturonase não foram detectadas no fruto; desta maneira, outras enzimas são responsáveis pela despolimerização das substâncias pécticas e consequiente amaciamento da polpa do fruto durante o amadurecimento.

\section{REFERÊNCIAS}

ABREU, C. M. P. Alterações no escurecimento interno e na composição química do abacaxi c.v. Smoth cayenne durante o seu amadurecimento com e sem refrigeração. 1991. 72f. Dissertação (Mestrado em Ciência dos Alimentos)-Escola Superior de Agricultura de Lavras, Lavras-MG.

ABREU, C. M. P. Efeito da embalagem de polietileno e da refrigeração no escurecimento interno e composição química durante a maturação de abacaxi c.v. Smoth cayenne. 1995. 94f. Tese (Doutorado em Ciência de Alimentos)-Universidade Federal de Lavras, Lavras$\mathrm{MG}$

ALONSO, J.; RODRIGUEZ, T.; CANET, W. Effect of calcium pretreatments on the texture of frozen cherries. Role of pectinesterase in the changes in the pectic materials. American Chemical Society, Washington, v.43, p.1011-1016, 1995.

ARÊAS, J.A.G.; LAJOLO, F. M. Determinação enzimática específica de amido, glicose, frutose e sacarose em bananas pré-climatéricas e climatéricas. Anais de Farmácia e Química de São Paulo, São Paulo, v.20, n1/2, p.307-318, jan/dez.1980.

ASSOCIATION OF OFFICIAL ANALYTICAL CHEMISTS. Official methods of analysis of the Association of the Analytical Chemistry. 15. ed. Arlington, $1990.2 \mathrm{v}$.

BITTER, T.; MUIR, H. M. A modified uronic acid carbazole reaction. Analitical Biochemistry, New York, v. 34, p. 330-334, 1962.
CHITARRA, M. I. F.; CHITARRA, A. B. Pós-colheita de frutos e hortaliças: fisiologia e manuseio. Lavras: ESAL/FAEPE, 1990. 320p. CORREAA, A. D.; ABREU, C. M. P de.; SANTOS, C. D.; RIBEIRO, L. J. Determinação de alguns constituinte químicos de interesse nutricional da fruta-de-lobo (Solanum lycocarpum St. Hil.). Ciências agrotécnicas, Lavras, v.24, n.1, p. 130-135, jan./mar. 2000.

CORREAA, M. P. Dicionário de plantas úteis do Brasil e exóticas cultivadas. Brasília: Ministério da Agricultura/Instituto Brasileiro de Desenvolvimento Florestal, 1984. 6v.

CUTILLAS-ITURRALDE, A.;ZARRA, I.; LORENCES, E. P. Metabolism of cell wall polysacharides from persimmon fruit. Pectin solubilization fruit ripening occurs in apparent absence of polygalacturonase activity. Physiologia Plantarum, Copenhagen, v. 89, p.369-375, 1993.

DALQVIST, Arne. Assay of intestinal disacaridases. Analytical Biochemistry, New York, v. 22, p.99-107. 1967.

FILGUEIRAS, H. A. C. Bioquímica do amadurecimento de tomates híbridos heterozigotos no loco 'alcobaça'. 1996. 118f. Tese (Doutorado em Ciência dos Alimentos)-Universidade Federal de Lavras, Lavras-MG.

GOLDSTEIN, J. L.; SWAIN, T. Changes in tannins in ripening fruits. Phytochemistry, Oxford, v.2, p.371-383, Oct. 1963.

KARDER, S.E.S.A.. Effect of gibberellic acid and vapor gard on ripening, amylase and peroxidase activities and quality of mango fruits during storage. Journal of Horticultural Science, Astiford, v. 67, n.6, p.855860, 1992.

MAARTEN, W. P. C. van Rossun; MARKA.; LINUS H. W. van ser Plas. Role of oxidative damage in tulip bulb scale micropropagation. Plant Science, Limerick, v.130, p.207-216, 1997.

McCREADY, R. M.; McCOMB, E. A. Extraction and determination of total pectic materials. Analytical Chemistry, Washington, v.24, n.12, p.1586-1588, 1952.

MENEZES, J. B. Qualidade pós-colheita do melão tipo 'Galia' durante a maturação e o armazenamento. 171f. Tese (Doutorado em Ciência dos Alimentos)-Universidade Federal de Lavras, Lavras-MG.

NELSON, N. A photometric adaptation of Somogyi method for the determination of glucose. Journal of Biological Chemists, Baltimore, v.153, n.1, p.375-380,1944.

NICOLAS, J. J.; RICHARD-FORGET, F. C.; GOUPY, P. M.; AMIOT, M. J.; AUBERT, S. Y. Enzymatic browning reactions in apple and apple products. Critical Reviews in Food Science Nutrition, Boca Raton, v.34, p.109-157, 1994.

NOELTING, G.; BERNFELD, P. Sur les enzimes amylolitiques. 111. La $\beta-$ amilase: dosage d'activité et controle de I'absence d'a-amilase. Helvetica Chemica Acta, Basel, v. 31, p.286-290, 1948.

OLIVEIRA JUNIOR, E. N. Alterações pós-colheita da fruta-de-lobo (Solanum lycocarpum St. Hil.) durante o amadurecimento. 2002. 71f. Tese (Mestrado em Agronomia)-Universidade Federal de Lavras, Lavras-MG.

OLIVEIRA JUNIOR, E. N.; SANTOS, C. D.; ABREU, C. M. P.; CORRÊA, A. D.; LOPEZ SANTOS, J. Z. Análise nutricional da fruta-de-lobo (Solanum lycocarpum St. Hil.) durante o amadurecimento. Ciência eAgrotecnologia, Lavras, v.27, n.4, p.846-851, jul./ago., 2003.

SEYMOUR, G. B.; TAYLOR, J. E.; TUCKER, G. A. Biochemistry of fruit ripening. London: CHAPMAN E HALL, 1993.454p.

SILVA, J.A.; SILVA, D. B.; JUNQUEIRA, N.T.V.; ANDRADE, L.R.M. Frutas nativas dos cerrados. Brasília: EMBRAPA, 1994. 166p.

VILAS BOAS, E. V.B. Modificações pós-colheita de banana "prata" (Musa acuminata $\boldsymbol{x}$ M. balbisiana grupo AAB) $\gamma$-irradiada. $73 \mathrm{f}$. Dissertação (Mestrado em Ciência dos Alimentos)-Universidade Federal de Lavras, Lavras. 